\title{
Identification of Layer Elastic Parameters for Angle-ply Laminated Plates and Shells (Comparison of Numerical and Experimental Results)
}

\author{
Kenji Hosokawa' \\ Faculty of Engineering, Chubu University \\ 1200 Matsumotocho, Kasugai, Aichi 487-8501 Japan \\ Kin'ya Matsumoto and Yasumasa Nakanishi \\ Faculty of Education, Mie University \\ 1515 Kamihamacho, Tsu, Mie 514-8507 Japan
}

\begin{abstract}
An inverse analysis method has already been proposed by the authors to identify elastic parameters for laminated composite materials using the experimental modal analysis technique, the FEM eigenvalue analysis and the nonlinear optimization method. To investigate the application of the proposed inverse analysis method, the method is applied to an angle-ply laminated square plate and an angle-ply laminated shallow cylindrical shell made of the same composite materials and made by the same curing condition. First, by applying the experimental modal analysis technique to the angle-ply laminated square plate and shallow cylindrical shell, natural frequencies and mode shapes are obtained. Next, by using the obtained natural frequencies and mode shapes, the layer elastic parameters for the test pieces are identified. On the other hand, the layer elastic parameters are experimentally measured with prepared specimen. These identified layer elastic parameters were compared, and found to agree well, with the measured layer elastic parameters.
\end{abstract}

" Corresponding Author:

Associate Professor Kenji Hosokawa

Faculty of Engineering, Chubu University

1200 Matsumotocho, Kasugai, Aichi 487-8501 Japan

Tel: $+81-568-51-1111$

Fax: +81-568-51-1194

E-mail: hosokawa@isc.chubu.ac.jp
Key Words: Identification, Elastic Parameters, Composite Material, FEM Eigenvalue Analysis, Nonlinear Optimization Method

\section{INTRODUCTION}

Since aerospace structures and sport goods require high specific strength and high specific modulus, many composite materials such as fiber reinforced plastics (FRP) have been used. It is therefore very important to make clear the mechanical behavior of the composite materials for the design and the structural analysis. Especially, elastic parameters are essential for the structural analysis. The elastic parameters of laminated composite materials, however, are difficult to determine ' by either theoretical or experimental approaches because of their anisotropy.

Using the modal test data, Carne and Martinez /1/ identified the material constants of an orthotropic shell. Deobald and Gibson $/ 2 /$ determined two Young's moduli, the in-plane shear modulus, and a Poisson ratio for aluminum plates and graphite-epoxy plates by using 
the natural frequencies measured by an impulse technique. Fällström and co-workers $/ 3-5 /$ determined material properties in orthotropic plates and anisotropic plates using the data obtained by the optical method. Ayorinde and Gibson /6, 7/ proposed an identification method for the four independent elastic constants of an orthotropic plate by using resonance data. Qian et al. /8/ presented a method for identifying elastic and damping properties of composite laminates by using measured complex modal parameters. A direct method of determining the six flexural stiffnesses of thin anisotropic plates was presented by Grediac and Paris 19/. Saito et al. /10/ identified the equivalent elastic parameters of honeycomb sandwich panels. On the other hand, one of the authors has already proposed an inverse analysis method to identify the elastic parameters for laminated composite materials using the FEM eigenvalue analysis and the sensitivity analysis $111,12 /$. It is an advantage of this method that one can obtain nondestructively the elastic parameters of the products made of composite materials. Also, the authors applied the proposed inverse analysis method to a symmetrically and an antisymmetrically laminated square plate /13/. Furthermore, the improved inverse analysis method was applied to a laminated circular cylindrical shell $/ 14 /$. From the comparison of these identified layer elastic parameters and ones obtained by another experimental method, one can see good agreement. Therefore, for the above-mentioned cases where the layer materials of the test pieces are different in each research work, it is evident that the proposed approach is applicable to the above-mentioned test pieces. Also, with respect to the identification of elastic parameters, we can find few publications in the literature for the simultaneously identified elastic parameters for the laminated plates and shells made of the same composite material.

In this paper, to demonstrate that the proposed approach is useful for laminated composite structures with various structural geometries, the proposed approach is applied to various laminated composite structures made of the same layer material and made by the same curing condition. Therefore, an angle-ply laminated square plate and an angle-ply laminated shallow cylindrical shell differing from the abovementioned test pieces (the symmetrically and antisymmetrically laminated square plates, the laminated circular cylindrical shell) are made of the same layer material and made by the same curing condition. The proposed method is applied to the angleply laminated square plate and the angle-ply laminated shallow cylindrical shell. The proposed method consists of the experimental modal analysis technique, the FEM eigenvalue analysis and the nonlinear optimization method considering the relation between elastic parameters and natural frequencies as a nonlinear system. First, by applying the experimental modal analysis technique to the angle-ply laminated square plate and shallow cylindrical shell, natural frequencies and mode shapes are obtained. Secondly, from the obtained natural frequencies and mode shapes, the layer elastic parameters are identified. Finally, to verify the identified layer elastic parameters, the layer elastic parameters are obtained experimentally. Good agreement is observed from a comparison of identified layer elastic parameters and experimental ones. Also, it is shown that the natural frequencies and mode shapes of test pieces estimated by using these identified layer elastic parameters agree well with experimental results.

\section{IDENTIFICATION METHOD}

The proposed identification method mainly consists of the experimental modal analysis technique, the FEM eigenvalue analysis and the nonlinear optimization method considering the relation between elastic parameters and natural frequencies as a nonlinear system. Since the identification method was described in detail in Ref. /14/, in the present paper, an application of the nonlinear optimization method and an outline will be presented.

Considering the relationship between natural frequencies and layer elastic parameters as a nonlinear system, quasi-Newton method can be used for identifying the layer elastic parameters relative to the material principal direction. We define the error function $g_{n}(x)$ as the difference between the $n$th natural frequency $f_{E n}$ measured by the experimental modal analysis technique and the calculated one $f_{n}(x)$ by the FEM eigenvalue analysis, as follows: 


$$
g_{n}(x)=f_{E n}-f_{n}(x)
$$

$\boldsymbol{x}$ are the layer elastic parameters in this case. Then, the identification is considered as a nonlinear optimization problem to find a solution $\boldsymbol{x}$ that minimizes the error norm $\Phi(x)$.

$$
\Phi(\boldsymbol{x})=\sum_{n=1}^{N T M} g_{n}(\boldsymbol{x})^{2}
$$

where $N T M$ is the total number of modes.

The quasi-Newton method takes an initial approximation $x_{0}$, and attempts to improve $x_{0}$ by the iteration formula using a search direction vector $\boldsymbol{d}$ and a step size parameter $\lambda$.

$$
x_{k+1}=x_{k}+\lambda_{k} d_{k}
$$

A step size parameter $\lambda$ is chosen by the line searcher algorithm, and a search direction vector $d$ can be given as a solution of the equation followed by

$$
H_{k} d_{k}=-\nabla \Phi\left(x_{k}\right)=-J^{T}\left(x_{k}\right) g\left(x_{k}\right)
$$

where $\boldsymbol{H}$ and $\boldsymbol{J}$ are the Hessian and Jacobian matrices of error function $g\left(x_{k}\right)$, respectively.

Figure 1 shows the flow chart of the identification program. Firstly, the data about the geometrical configuration, initial material properties of the test piece, and natural frequencies measured by an excitation test are given. Secondly, to calculate the natural frequencies and mode shapes, an eigenvalue analysis is carried out using the initial parameters. Next, the error function $g(x)$ is estimated by the difference of the natural frequencies obtained by the eigenvalue analysis and the experiment. In this phase, since the order of the natural modes may be replaced by the ratio of the elastic moduli of anisotropic materials, the order of the natural modes is investigated by $M A C$ (Modal Assurance Criterion) $/ 15 /$. After that, the layer elastic parameters are identified by quasi-Newton method. Finally, if the error norm $\Phi(x)$ shown in equation (2) is converged, the identification program is terminated.

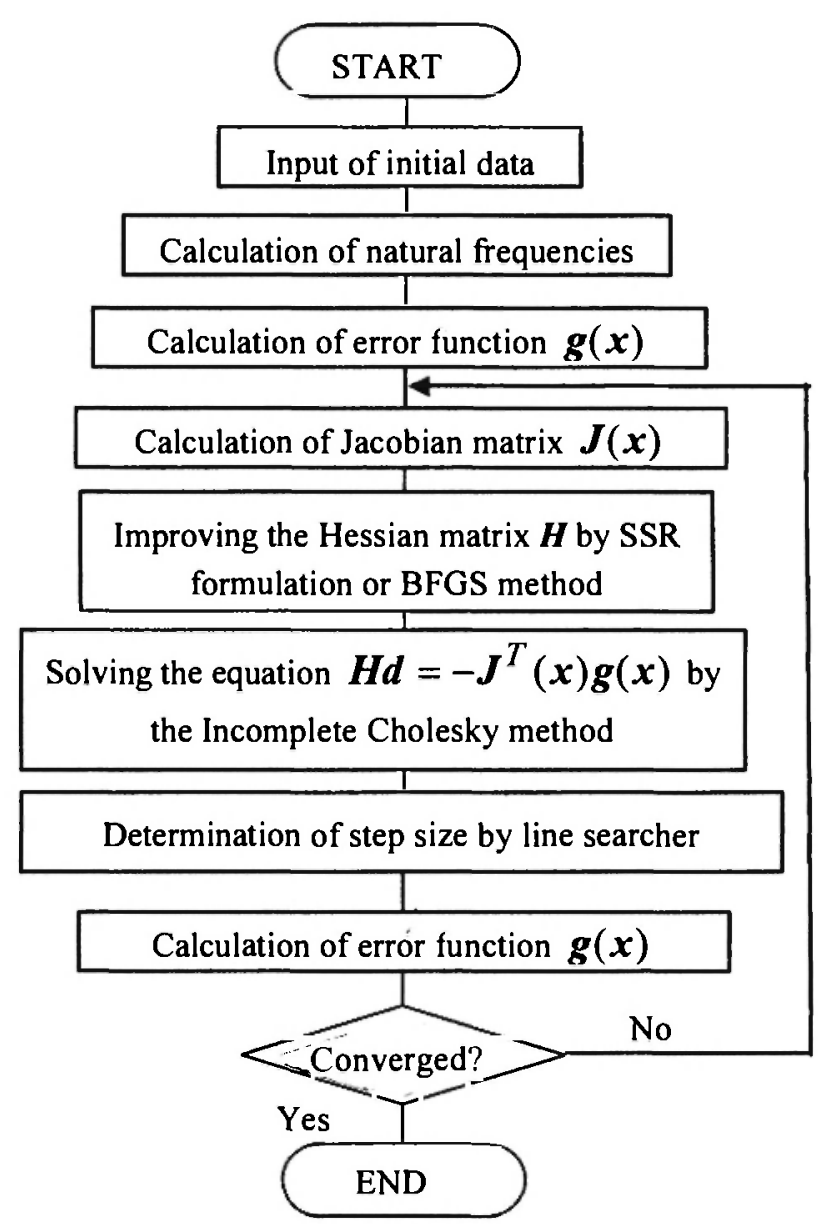

Fig. 1: Flow chart of identification program

\section{IDENTIFICATION OF LAYER ELASTIC PARAMETERS}

To identify the layer elastic parameters for the angle-ply laminated square plate and shallow cylindrical shell, experimental modal analyses were carried out. Each layer material, that is lamina, is reinforced by carbon fibers. This fiber's tensile elastic modulus is 230 [GPa]. The matrix is an epoxy resin $\left(130^{\circ} \mathrm{C}\right.$ cure). The fiber volume fraction is 55 [\%]. The laminae of the plate and shell are made of the same layer material and the both test pieces were made under the same curing condition. As such, the layer elastic moduli of the laminated square plate and shallow cylindrical shell are due to have few differences. As shown in Fig. 2, the configuration of the shallow cylindrical shell is a square planform ( $a=b=0.2[\mathrm{~m}])$. The shell's thickness $h$ is 1.60 


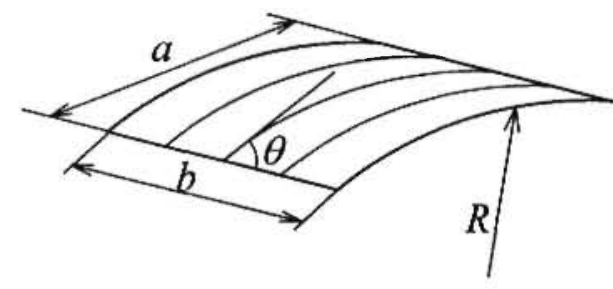

Fig. 2: Laminated shallow cylindrical shell

$\times 10^{-3}[\mathrm{~m}]$. The inside radius $R$ of the shell is $0.4[\mathrm{~m}]$. The density and the stacking sequence of the angle-ply laminated shallow cylindrical shell are $1529\left[\mathrm{~kg} / \mathrm{m}^{3}\right]$ and $\left[30^{\circ}{ }_{2} /-30^{\circ}{ }_{2} /-30^{\circ}{ }_{2} / 30^{\circ}{ }_{2}\right]$, respectively. The stacking sequence of the angle-ply laminated square plate is the same that of the laminated shallow cylindrical shell. The density of the laminated plate is $1525\left[\mathrm{~kg} / \mathrm{m}^{3}\right]$. The dimensions of the plate are of $0.2[\mathrm{~m}]$ long and $0.2[\mathrm{~m}]$ wide. The thickness of the laminated square plate is $1.61 \times 10^{-3}[\mathrm{~m}]$.

\subsection{Natural Frequency and Mode Shape}

To satisfy the free boundary conditions on all four edges, each test piece was hung from the ceiling by a fine string. The plate and shell were divided into $8 \times 8$ areas and 81 dividing points were used as reference points. To measure the transfer function (accelerance), an accelerometer was attached to one reference point and then all reference points were impacted by an impulse force hammer (see Fig. 3). The mass of the accelerometer is $0.48[\mathrm{~g}]$. From the obtained transfer function, the natural frequencies and mode shapes of the test pieces were estimated by applying the experimental modal analysis technique. Figure 4 shows the experimentally obtained first six natural frequencies and mode shapes of each test piece. In this paper, for the mode shapes of the laminated shell, upper and lower edges are the curved edges.

\subsection{Identified Layer Elastic Parameters}

From the experimental natural frequencies and mode shapes shown in Fig. 4, the layer elastic parameters for the angle-ply laminated square plate and shallow cylindrical shell were estimated by the proposed identification method. The computations were carried out using the FEM eigenvalue program with triangular shell elements. Each test piece is divided into 800 elements with 441 nodal points. In the numerical calculations, the mass of the accelerometer was not considered because the mass of the accelerometer is very small. Table 1 shows the error norm estimated by equation (2) and the maximum error existed between the numerical and experimental natural frequencies. From this table, we can find that the error norm and the maximum error are converged regardless of the reference mode number.

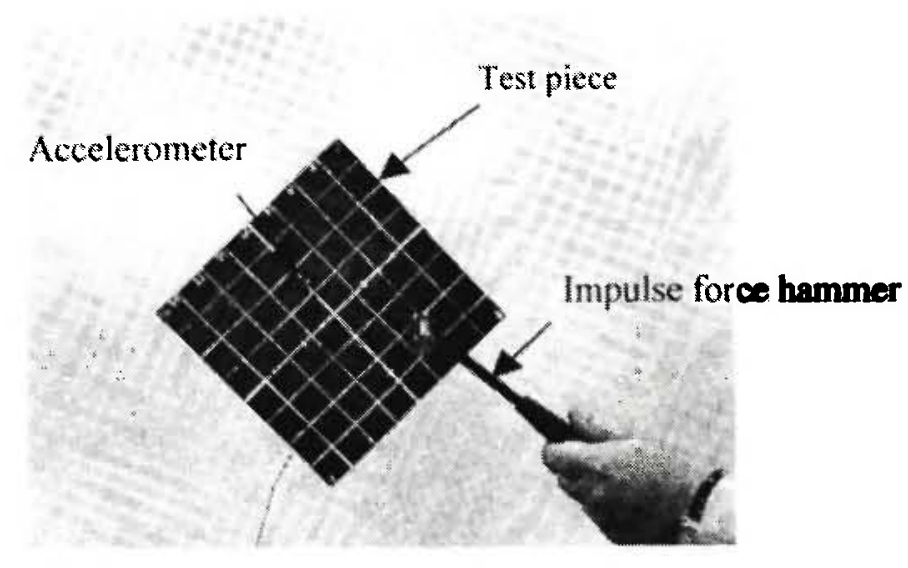

Fig. 3: Measurement of natural frequencies and mode shapes by experimental modal analysis technique 


\begin{tabular}{|c|c|c|c|c|c|c|c|}
\hline Test piece & Modal order & $1 \mathrm{st}$ & 2nd & 3 rd & 4th & 5 th & 6th \\
\hline \multirow{2}{*}{$\begin{array}{l}\text { Angle-ply } \\
\text { laminated } \\
\text { plate }\end{array}$} & Mode shape & & & & & & \\
\hline & $\begin{array}{l}\text { Natural } \\
\text { frequency }[\mathrm{Hz}]\end{array}$ & 101.3 & 112.4 & 254.9 & 273.2 & 286.7 & 416.2 \\
\hline \multirow{2}{*}{$\begin{array}{l}\text { Angle-ply } \\
\text { laminated } \\
\text { shell }\end{array}$} & Mode shape & & & & & & \\
\hline & $\begin{array}{l}\text { Natural } \\
\text { frequency [Hz] }\end{array}$ & 103.3 & 161.3 & 267.4 & 362.7 & 465.1 & 547.0 \\
\hline
\end{tabular}

Fig. 4: Experimental natural frequencies and mode shapes of test pieces

Table 1

Error norm and maximum error

\begin{tabular}{|l|ccc|}
\hline Test piece & $\begin{array}{c}\text { Reference } \\
\text { mode number }\end{array}$ & $\begin{array}{c}\text { Error } \\
\text { norm }\end{array}$ & $\begin{array}{c}\text { Maximum } \\
\text { error } \\
{[\%]}\end{array}$ \\
\hline Angle-ply & 4 & 3.2 & 2.5 \\
Laminated & 5 & 3.2 & 2.5 \\
plate & 6 & 3.2 & 2.6 \\
\hline Angle-ply & 4 & 4.0 & -2.8 \\
Laminated & 5 & 2.9 & -2.8 \\
shell & 6 & 3.2 & -3.0 \\
\hline
\end{tabular}

The identified layer elastic parameters are shown in Table 2. In Table 2, the elastic moduli $E_{L}, E_{T}$ in the direction of the parallel and normal to the fiber and shear modulus $G_{L T}$ are shown. Poisson's ratio $v_{L T}$ is assumed to be 0.35 . Table 2 shows the effect of the number of reference modes on the convergence of the identified layer elastic parameters. From this table, it follows that one can identify sufficiently converged values for the angle-ply laminated square plate compared with the identification of the layer elastic parameters for the angle-ply laminated shallow cylindrical shell. It is considered that the convergence of the identified layer elastic parameters for the angle-ply laminated shallow cylindrical shell is improved by using more triangular shell elements in the FEM eigenvalue analysis. However, one can find good agreement between the identified layer elastic parameters of the angle-ply laminated square plate and ones of the angleply laminated shallow cylindrical shell. The difference between the identified layer elastic parameters of the plate and those of the shell is no more than $8.9 \%$.

Table 2

Identified layer elastic parameters

\begin{tabular}{|l|cccc|}
\hline Test piece & $\begin{array}{c}\text { Reference } \\
\text { mode number }\end{array}$ & $\begin{array}{c}E_{L} \\
\text { [GPa] }\end{array}$ & $\begin{array}{c}E_{T} \\
\text { [GPa] }\end{array}$ & $\begin{array}{c}G_{L T} \\
\text { [GPa] }\end{array}$ \\
\hline Angle-ply & 4 & 111 & 8.54 & 3.86 \\
Laminated & 5 & 110 & 8.67 & 3.95 \\
plate & 6 & 110 & 8.64 & 3.95 \\
\hline Angle-ply & 4 & 116 & 7.95 & 3.46 \\
Laminated & 5 & 115 & 8.23 & 4.71 \\
shell & 6 & 118 & 8.26 & 4.34 \\
\hline
\end{tabular}

\section{VERIFICATION OF IDENTIFIED LAYER ELASTIC PARAMETERS}

To verify the identified layer elastic parameters for the laminated plate and shell, elastic parameters of the specimen were obtained experimentally. To exclude the 
effects of the stacking sequence and the fiber orientation angle, single layer beam type specimens with fiber orientation angles of $0^{\circ}, 45^{\circ}$ and $90^{\circ}$ were made of graphite/epoxy which was used as the lamina to make the laminated plate and shell. The dimensions of the specimens are $0.30[\mathrm{~m}]$ long, $0.025[\mathrm{~m}]$ wide and $1.0 \times$ $10^{-3}$ [m] thick. The density of these beam type specimens is $1518\left[\mathrm{~kg} / \mathrm{m}^{3}\right]$. These specimens have the same volume fraction as the laminated plate and shell. The elastic moduli $E_{L}$ and $E_{T}$ were estimated numerically from the fundamental natural frequencies obtained by forced vibration tests of the specimen as shown in Fig.5. Poisson's ratio $v_{L T}$ was obtained by

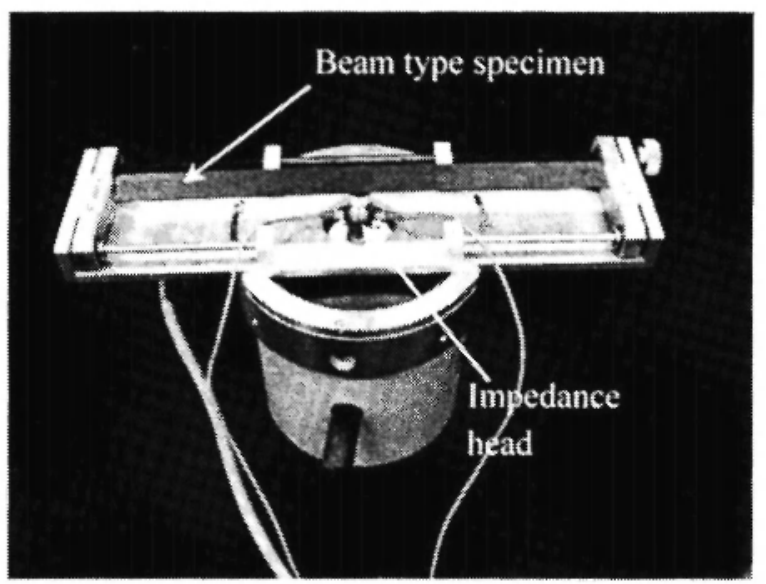

Fig. 5: Measurement of natural frequencies by forced vibration test the tensile test of the specimen with fiber orientation angle of $0^{\circ}$. The shear modulus $G_{L T}$ was estimated numerically from the elastic moduli of each specimen and the Poisson ratio $/ 16 /$. The measured material properties of the layer are listed in Table 3. From the comparison between Table 2 and Table 3, one can see the good agreement between identified and experimental layer elastic parameters except for the shear modulus of the angle-ply laminated plate (difference is about $15 \%$ ). It is considered that the experimental accuracy of the angle-ply laminated plate decreases compared to the experimental results of angle-ply laminated shell since the third to fifth natural frequencies of the laminated square plate are much close. To confirm the identified layer elastic parameters, the FEM eigenvalue analysis was carried out by using the identified results. For the computation of natural frequencies and mode shapes, the mass of accelerometer was neglected since it is very small compared to the test pieces' mass. Figure 6 shows the natural frequencies and mode shapes of these test pieces estimated by the eigenvalue analysis. From Figure 4 and Figure 6, one can see that the difference between the experimental and

Table 3

Material properties of layer obtained by experiment

\begin{tabular}{|cccc|}
\hline$E_{L}[\mathrm{GPa}]$ & $E_{T}[\mathrm{GPa}]$ & $G_{L T}[\mathrm{GPa}]$ & $v_{L T}$ \\
\hline 115 & 8.88 & 4.64 & 0.35 \\
\hline
\end{tabular}

\begin{tabular}{|c|c|c|c|c|c|c|c|}
\hline Test piece & Modal order & 1 st & 2nd & $3 r d$ & 4th & 5 th & 6th \\
\hline \multirow{2}{*}{$\begin{array}{l}\text { Angle-ply } \\
\text { laminated } \\
\text { plate }\end{array}$} & Mode shape & & & & & & \\
\hline & $\begin{array}{l}\text { Natural } \\
\text { frequency }[\mathrm{Hz}]\end{array}$ & 101.0 & 115.3 & 255.7 & 268.3 & 284.8 & 415.3 \\
\hline \multirow{2}{*}{$\begin{array}{l}\text { Angle-ply } \\
\text { laminated } \\
\text { shell }\end{array}$} & Mode shape & & & & & & \\
\hline & $\begin{array}{l}\text { Natural } \\
\text { frequency }[\mathrm{Hz}]\end{array}$ & 102.6 & 156.4 & 265.9 & 360.1 & 466.1 & 550.0 \\
\hline
\end{tabular}

Fig. 6: Numerical natural frequencies and mode shapes of test pieces 
the numerically calculated natural frequencies is no more than $3.0 \%$ and one can find good agreements between these mode shapes of the test pieces.

\section{CONCLUSIONS}

The inverse analysis method to identify layer elastic parameters for laminated composite structures was applied to an angle-ply laminated square plate and an angle-ply laminated shallow cylindrical shell made of the same composite materials and made by the same curing condition. One can find good agreement between the identified layer elastic parameters for the angle-ply laminated square plate and that of the angle-ply laminated shallow cylindrical shell. On the other hand, the layer elastic parameters for the laminated plate and shell were obtained experimentally. From the comparison between identified layer elastic parameters and experimental ones, one can see good agreement between these layer elastic parameters. Also, to confirm the identified layer elastic parameters, the FEM eigenvalue analysis was carried out by using the identification results. From the results, one can see good agreement with respect to the natural frequencies and mode shapes. Accordingly, it follows that one can accurately estimate layer elastic parameters for the laminated composite structures by using the proposed inverse analysis method.

\section{REFERENCES}

1. T. G. Carne and D. R. Martinez, "Identification of material constants for a composite shell structure," in 5th International Modal Analysis Conference, 1, 660-670 (1987).

2. L. R. Deobald and R. F. Gibson, "Determination of elastic constants of orthotropic plates by a modal analysis / Rayleigh-Ritz technique," Journal of Sound and Vibration, 24(2):269-283 (1988).

3. K-F Făllström and N-E.A Molin, "Nondestructive method to determine material properties in orthotropic plates," Polymer Composites, 8(2): 103108 (1987).

4. K-F Făllstrơm and M., A Jonsson, "Nondestructive method to determine material properties in anisotropic plates," Polymer Composites, 12(5):293-305 (1991).

5. K-F Făllstrơm, "Determining material properties in anisotropic plates using Rayleigh's method," Polymer Composites, 12(5):306-314 (1991).

6. E. O. Ayorinde and R. F. Gibson, "Elastic constants of orthotropic composite materials using plate resonance frequencies, classical lamination theory and an optimized three-mode Rayleigh formulation," Composites Engineering, 3(5):180186 (1993).

7. E. O. Ayorinde and R. F. Gibson, "Improved method for in-situ elastic constants of isotropic and orthotropic composite materials using plate modal data with trimodal and hexamodal Rayleigh formulations," Journal of Vibration and Acoustics (Transactions of the American Society of Mechanical Engineers), 117(1):180-186 (1995).

8. G. Qian, S. V. Hoa, and X. Xiao, "Identification of elastic and damping properties of composite laminates from vibration test data," in ICCM-10, 4: 25-32 (1995).

9. M. Grédiac and P.A. Paris, "Direct identification of elastic constants of anisotropic plates by modal analysis: theoretical and numerical aspects," Journal of Sound and Vibration, 195(3):401-415 (1996).

10. T. Saito, R. D. Parbery, S. Okuno, and S. Kawano, "Parameter identification for aluminum honeycomb sandwich panels based on orthotropic Timoshenko beam theory," Journal of Sound and Vibration, 208(2):271-287 (1997).

11. K. Matsumoto, M. Zako, and M. Furuno, "Identification of anisotropic parameters for hybrid laminated composites using FEM eigenvalue analysis," Transactions of the Japan Society of Mechanical Engineers (in Japanese), 62(596): 1341-1346 (1996).

12. K. Matsumoto, M. Zako, M. Furuno, and T. Fujita, "Inverse problem to identify equivalent elastic parameters of honeycomb sandwich panels," Transactions of the Japan Society of Mechanical Engineers (in Japanese), 63(611):2256-2261 (1997).

13. K. Hosokawa, K. Matsumoto, and M. Zako, 
"Identification of elastic parameters for laminated composites using FEM eigenvalue analysis (Comparison of numerical and experimental results)," Fatigue, Environmental Factors, and New Materials (Proceedings of PVP Conference), PVP-374:325-329 (1998).

14. K. Hosokawa and K. Matsumoto, "Identification of elastic parameters for laminated circular cylindrical shells (Comparison of numerical and experimental results)," JSME International Journal, Series C, 45(1):26-31 (2002).

15. D. J. Ewins, "Modal Testing: Theory, Practice and Application", Research Studies Press Ltd., Baldock, Hertfordshire, England: 422-427, 2001.

16. R. M. Jones, "Mechanics of Composite Materials", Taylor \& Francis, Inc. Philadelphia, PA, USA: 91100, 1999. 